\title{
Genetic Susceptibility to Oral Cancer due to Combined Effects of GSTT1, GSTM1 and CYP1A1 Gene Variants in Tobacco Addicted Patients of Pashtun Ethnicity of Khyber Pakhtunkhwa Province of Pakistan
}

\author{
Zakiullah $^{1 \& *}$,Ahmadullah ${ }^{2 \&}$,Muhammad Khisroon ${ }^{2}$,Muhammad Saeed ${ }^{1 *}$, Ajmal \\ Khan $^{2}$, Fazli Khuda ${ }^{1}$, Sajid Ali ${ }^{3}$, Nabila Javed ${ }^{4}$, Muhammad Ovais ${ }^{6}$, Nosheen \\ Masood $^{5}$, Nasir Khan Khalil ${ }^{1}$, Mohammad Ismail ${ }^{1}$
}

\begin{abstract}
Associations of GSTT1, GSTM1 and CYP1A1 gene variants with risk of developing oral cancer were evaluated in this study. A case-control study was conducted in Pashtun population of Khyber Pakhtunkhwa province of Pakistan in which 200 hospital based oral cancer cases and 151 population based healthy controls exposed to similar environmental conditions were included. Sociodemographic data were obtained and blood samples were collected with informed consent for analysis. GSTM1 and GSTT1 were analysed through conventional PCR method while specific RT-PCR method was used to detect CYP1A1 polymorphisms. Results were analyzed for conditional logistic regression model by SPSS version 20. The study shows that patients with either GSTM1 or GSTT1 null genotypes have significantly higher risk of oral cancer (adjusted odds (OR): (3.019 (1.861-4.898) and 3.011(1.865-4.862), respectively), which further increased when either one or both null genes were present in combination (adjusted odds (OR): (3.627 (1.981-6.642 and 9.261 (4.495-19.079), respectively). CYP1A1 rs4646903 gene variants individually showed weak association OR: 1.121 (0.717-1.752); however, in the presence of GSTM1 and/or GSTT1 null genotypes further increasing the association (adjusted odds (ORs): 4.576 (2.038-10.273), 5.593 (2.530-12.362) and 16.10 (3.854-67.260 for GSTM/GSTT null and CYP1A1 wild type, GSTM/GSTT either null and CYP1A1 variant alleles, and all 3 gene polymorphisms combinations, respectively). Our findings suggest that presence of GSTM1 and/or GSTT1 null genotypes along with variant alleles of CYP1A1 may be the risk alleles for oral cancer susceptibility in Pashtun population.
\end{abstract}

Keywords: Oral cancer risk - GSTT1 - GSTM1 and CYP1A1 gene variants - Pashtun population - Pakistan

Asian Pac J Cancer Prev, 16 (3), 1145-1150

\section{Introduction}

Oral cancer is the fourth most common cancer in the world (Amtha et al., 2009; Gupta and Johnson, 2014). It is estimated that over 400,000 cases occur annually with a wide variation in global burden. Its incidence in South and South East Asia is amongst the highest in the world. Incidence is also on the rise in Western and Eastern Europe, Latin America and Pacific regions (Ariyawardana and Johnson, 2013). In Pakistan oral cancer is the second most common malignancy after breast cancer and is significantly higher than other member states of the World Health Organization's Eastern Mediterranean (WHOEMRO) Region (Bile et al., 2010).

Tobacco use and alcohol drinking are the main independent risk factors for the development of head and neck area cancers, especially that of the oral cavity (Warnakulasuriya et al., 2005; Amtha et al., 2009). In Pakistan, about $50 \%$ tumors in males and $25 \%$ those of in females are associated with consumption of tobacco products (Warnakulasuriya et al., 2005; Bhurgri et al., 2006). In Bangladesh and India, about one-third of all cancers are tobacco-related. High incidence of oral and pharyngeal cancers has been reported in South Asia, even among female population, for which smokeless tobacco products are considered to be the most prominent risk factor (Moore et al., 2000; Gupta and Johnson, 2014). Association of oropharyngeal cancer with smokeless tobacco products is reportedly four times higher relative to no history of tobacco use after adjusting for confounding factors (Merchant 2000; Bile et al., 2010). Similarly pan with or without tobacco has been associated with oral

${ }^{1}$ Department of Pharmacy, ${ }^{2}$ Department of Zoology, ${ }^{4}$ Institute of Radiotherapy \& Nuclear Medicine,${ }^{6}$ Centre of Biotechnology \& Microbiology, University of Peshawar, Peshawar, ${ }^{3}$ Department of Biotechnology, Abdul Wali Khan, University Mardan, ${ }^{5}$ Fatima Jinnah Women University, Rawalpindi, Pakistan*For correspondence: saeedrph@upesh.edu.pk; zakiullah@upesh.edu.pk 
cancer (Merchant et al., 2000). Several studies from India and Pakistan have provided sufficient evidence that use of tobacco mixed with lime and chewing betel quid containing tobacco were carcinogenic to humans with significant dose-response relationships for frequency of chewing per day and for duration of tobacco consumption (Rao and Desai, 1998; Nandakumar et al., 1990; Dikshit and Kanhere, 2000; Balaram et al., 2002; Znaor et al., 2003).

Tobacco products contain more than 30 carcinogens. However, studies on the mechanism of their carcinogenesis suggest that three classes among them are of major importance i.e., Tobacco Specific Nitrosamines (TSNAs), Poly Aromatic Hydrocarbons (PAHs) and aromatic amines (Rickert et al., 2009). These compounds are actually procarcinogens and are metabolized by Xenobiotic metabolizing enzymes, namely Cytochrome P450 (CYPs) and Glutathione-S-transferases (GSTs). The former is involved in their activation to carcinogenic species; while the latter is involved in their detoxification and excretion from the body (Zakiullah et al., 2014). Various isoforms of CYPs including CYP1A1 are reportedly involved in activation process (D'Errico et al., 1996; Olshan et al., 2000). Similarly among GSTs, M1 (GSTM1) and T1 (GSTT1) enzymes are more important in detoxification (Nair et al., 1999).

However, the expression of these enzymes differs in individuals resulting in differences in the metabolic processing of carcinogens. Certain individuals are genetically more susceptible to cancer when exposed to carcinogens owing to their genotype for enzymes responsible for their activation or detoxification (Abbas et al., 2014). This is evident from the general observation that only a small number of individuals among those exposed to tobacco or alcohol under the same environmental conditions develop cancer in their life time. Allelic variants influencing the enzyme activity of CYP1A1 along with environmental factors such as tobacco use play key roles in making individuals susceptible to different types of cancers (Xia et al., 2013). The CYP1A1 gene located on chromosome 15q22-q24 encodes an enzyme with aryl hydrocarbon hydroxylase activity that plays important role in the metabolism of polycyclic aromatic hydrocarbons (PAH) and nitrosamines from tobacco, and inherited differences in metabolic capacity are considered to contribute significantly in carcinogenesis (Sabitha et al., 2010). Certain allelic variations in the CYP1A1 gene and prolonged exposure to tobacco products could lead to higher levels of reactive metabolites, thereby causing DNA damage in addition to other contributing factors (Prokopczyk et al., 1997; Velema et al., 2002). Similarly deletion of genes responsible for GSTs results in a lack of enzyme activity and consequently a decrease in the elimination of carcinogenic species. Two of the GSTs i.e., GSTT1 and GSTM1 have been extensively explored in relation to several types of cancers (Amtha et al., 2009; Nosheen et al., 2014). They both detoxify major tobacco related carcinogens and their absences increase the risk of a variety of cancers of different areas including that of the mouth, lung, bladder and breast (Nosheen et al., 2014). Loss of GSTM1 enzymatic activity due to homozygous null genotype reportedly occurs in about $50 \%$ of Asians and Caucasians (Amtha et al., 2009, Nosheen et al., 2014). Previous studies on the association of oral cancer with polymorphism in these genes have shown varying results. Some studies have shown the association of polymorphisms in CYP1A1 and GSTM1 genes with oral cancer (Tanimoto et al., 1999; Wogan et al., 2004), while some studies have reported a lack of association (Park et al., 2000; Olshan et al., 2000; Sreelekha et al., 2001; Sharma et al., 2006; Cha et al., 2007). These seemingly conflicting observations are due to geographic and ethnic variations in the distribution of genotype frequencies of both CYP and GST alleles along with other environmental factors. A recent study has emphasized on the inclusion of country of study, source of population, specific ethnicity and characteristics of general demographic variables in future studies to deduce conclusive and more reliable results (Nosheen et al., 2014).

Association of genetic polymorphisms of the above mentioned genes with oral cancer has not been so far reported in Pashtun population of Khyber Pakhtunkhwa province of Pakistan. Therefore, a case-control study was carried out to evaluate the potential role of CYP1A1 $(\mathrm{T}>\mathrm{C}$, rs4646903), GSTM1 and GSTT1 gene polymorphisms in the susceptibility to oral cancer in Pashtun population of Khyber Pakhtunkhwa province of Pakistan. This will help to adopt pro-active approaches for early detection and preventive life style modification strategies to decrease the incidence of the disease in the target population.

\section{Materials and Methods}

\section{Sample collection}

Study sample comprised of 200 oral cancer patients and 151 healthy control subjects between 30 and 70 years of age as per exclusion/inclusion criteria. Patients were registered at the Institute of Radiotherapy and Nuclear Medicine (IRNUM), Peshawar, Khyber Pakhtunkhwa; while eligible control samples were collected from various districts of the same province. The study period was from July, 2012- July, 2013. All the patients were having histopathologically confirmed oral cancer.

Inclusion criteria (patients): Histo-pathologically proven oral cancer patients having age between 30 and 70 years with Pashtun ethnicity, and not less than 20 years of tobacco exposure in any form. Exclusion criteria (patients): Patients with non-Pashtun ethnicity and/or having more than 70 years of age. Criteria for selection of control subjects: Normal healthy age-matched subjects of similar ethnicity with not less than 20 years of exposure to tobacco in any form, and free from cancer.

Study was approved from the Ethical Committee of the Department of Pharmacy, University of Peshawar (No. 440, dated 17.12.2011). Informed consent and thorough interview was taken by expert in the relevant field before blood collection on a carefully designed proforma that contained information regarding age, place, occupation, socioeconomic status, cancer type and tobacco use habits etc. Three milliliters of whole blood was collected from all subjects in properly labelled EDTA tubes and genomic DNA was subsequently extracted by using standard DNA 

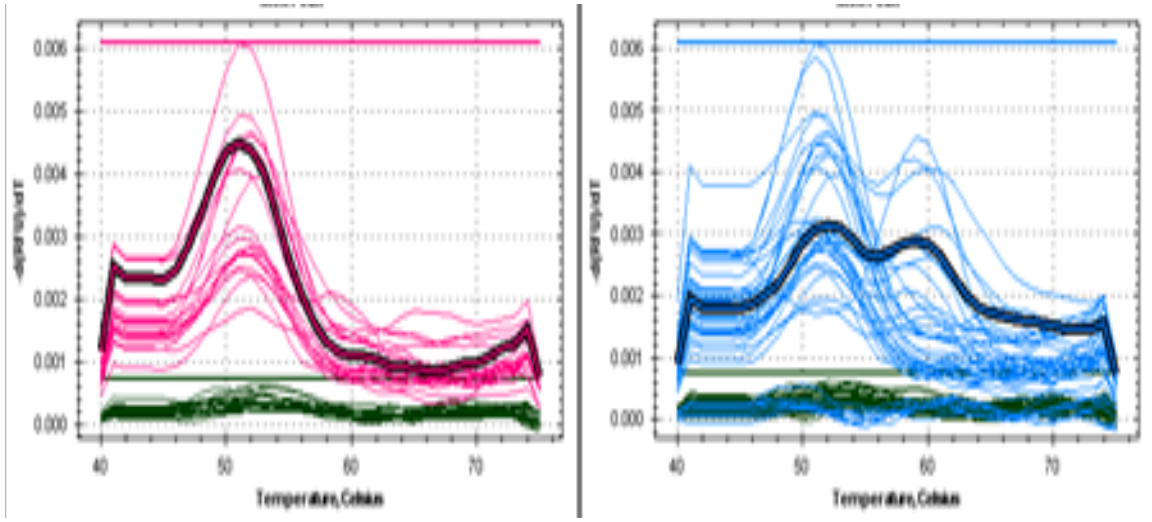

Figure 1. Representative Melting Peaks of RT-PCR of CYP1A1 rs4646903 polymorphism: Pink peaks represent CYP1A1 wild type (T/T), while blue peaks show variant alleles (T/C and C/C)

Isolation kit (Purelink Genomic DNA kit Invitrogen, USA) as per manufacturer's recommendations. The DNA quality and quantity were determined using a double beam spectrophotometer (Perkin Elmer series 200 system, Norwalk, USA).

\section{Genotyping of CYP1A1 (T>C, rs4646903)}

The CYP1A1 (T>C, rs4646903) polymorphisms were analyzed using a highly specific Real Time Polymerase Chain Reaction (RT-PCR). Light SNiP rs4646903 (primers and probes) and FastStart DNA Master Hyprobe kit were purchased from Tib-Molbiol (Germany) and Roche Diagnostics (Germany), respectively. Reaction was performed as per supplier's recommendation as follows. Reaction mix comprised of Reagent Mix $(1 \mu 1)$, FastStart DNA Master $(2 \mu \mathrm{l})$, Magnesium chloride $(25 \mathrm{~mm}, 1.6 \mu \mathrm{l})$, and water (14.4 1$)$. Finally, DNA $(1 \mu 1,100-150 \mathrm{ng})$ was added to the reaction mix to make the final volume $20 \mu 1$. Thermocycler (MiniOpticon Model CFB-3120EDUUSA) conditions were as follows: Denaturation at $95^{\circ} \mathrm{C}$ for 10 minutes; Cycling for 45 cycles of $95^{\circ} \mathrm{C}$ for 10 seconds, $45^{\circ} \mathrm{C}$ for 60 seconds and $72^{\circ} \mathrm{C}$ for 15 seconds; followed by melting curves analysis at $95^{\circ} \mathrm{C}$ for 10 seconds, $40^{\circ} \mathrm{C}$ for 2 minutes through $75^{\circ} \mathrm{C}$ for 0 seconds. Duplicate samples were used as control. Melting peaks at $51-52{ }^{\circ} \mathrm{C}$ represented wild type (T/T) allele; the one at $59-60{ }^{\circ} \mathrm{C}$ represented variant $(\mathrm{C} / \mathrm{C})$ allele, while samples giving two peaks at $51^{\circ} \mathrm{C}$ and $59^{\circ} \mathrm{C}$ were heterozygous (T/C) allele (Figure 1).

\section{Genotyping assay for GSTM1 and GSTT1}

For the determination of homozygous null polymorphisms of GSTM1 and GSTT1 new conventional PCR methods were developed and optimized for individual genes. Primer sets (designed through Primer3Plus online software) used was 5'-CATGTGACAGTATTCTTATTTC3', 5' - ACTCAATCTCAGCATCACAGC- 3' and 5' - ATCTGTGGTCCCCAAATCAG-3', 5' GGGGGTTGTCTTTTGCATAG-3', for GSTM1 and GSTT1 respectively. Duplicate samples were used as positive control for both genes. PCR was separately performed for both genes in a $25 \mu \mathrm{l}$ reaction mixture containing $20 \mathrm{mM}$ Tris- $\mathrm{HCl} \mathrm{pH} 9.0,50 \mathrm{mM} \mathrm{KCl}, 2$ $\mathrm{mM} \mathrm{MgCl}$ 2, $200 \mu \mathrm{M}$ dNTPs (Promega, USA), primers (Macrogen, South Korea) 10 pmol of each set individually, 0.5 units of Taq DNA polymerase (Bio-Labs, UK), and 50-
100 ng of genomic DNA. PCR was individually performed in the GeneAmp PCR system 9700 (Applied Biosystems, USA). After an initial denaturation at $95^{\circ} \mathrm{C}$ for 4 minutes, amplification was carried out for 40 cycles at $95^{\circ} \mathrm{C}$ for 30 seconds, $52^{\circ} \mathrm{C}$ for 45 seconds and $72^{\circ} \mathrm{C}$ for 1 minute for GSTM1 and $55^{\circ} \mathrm{C}$ for 45 seconds and $72^{\circ} \mathrm{C}$ for 1 minute for GSTT1, followed by final elongation at $72^{\circ} \mathrm{C}$ for 10 minutes. The PCR products were electrophoresed in a 1 $\%$ agarose gel for analysis. GSTM1 and GSTT1 genotype were identified by the presence of a band at 298 and 632 bp respectively (Figures 2 and 3).

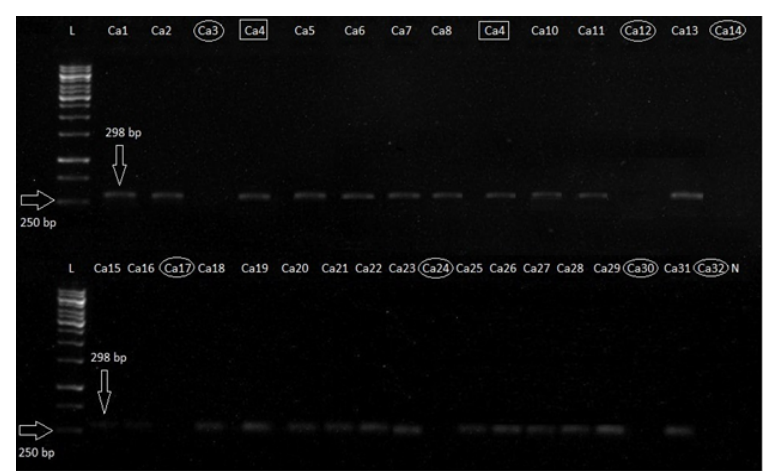

Figure 2. A Representative image of PCR analysis of GSTM1 Polymorphisms. L is molecular weight marker $(1 \mathrm{~kb}) . \mathrm{N}$ is negative control. Cal to Ca32 are oral cancer samples. Duplicate sample Ca4 was used as positive control (shown in square). GSTM1 wild type was shown at 298bp as indicated by vertical arrow, whereas GSTM1 Null has been shown in circles

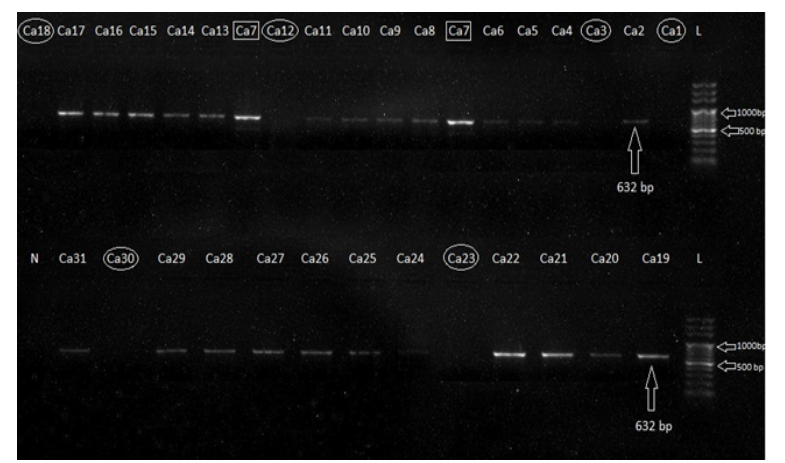

Figure 3. A Representative Image of PCR analysis of GSTT1 Polymorphisms. L is molecular weight marker (100bp) $\mathrm{N}$ is negative control. Cal to Ca31 are oral cancer samples. Duplicate sample Ca7 was used as positive control (shown in square). GSTT1 wild type was shown at 632 bp as indicated by vertical arrow, whereas GSTT1 Null has Been shown in circles 


\section{Statistical analysis}

Chi-square $\left(\chi^{2}\right)$ test was used to detect whether there were significant $(\alpha=0.05)$ differences in frequencies of genes. Odds Ratios (OR) for each polymorphism using binary logistic regression model were estimated with $95 \%$ confidence intervals (CIs), and the difference in genotype prevalence and association between case and control group were assessed independently as well as adjusted for confounding factors. Age, gender, place of residence, tobacco type used, amount of tobacco used per day and age at first exposure were included as covariates as well as all the possible genotypes studied. GSTM1 and GSTT1 were categorized on the basis of presence and absence (null genotype) of the gene, while CYP1A1 rs4646903 polymorphism was classified into homozygous wild type and variant allele containing genotypes. Wild type was used as reference group to assess the effects of the different alleles. Analyses were performed by SPSS (Version 20.0).

\section{Results}

\section{Subject characteristics}

Demographic and other subject characteristics are shown in Table 1. Mean age of healthy subjects (controls) and esophageal cancer patients was $56.14 \pm 07.91$ and $54.88 \pm 9.83$ years, respectively $(t$ test $p$ value $=0.931)$.

Table 1. Demographic Characteristics of the Subjects

\begin{tabular}{|c|c|c|c|}
\hline Variables & Controls & Cases & p-value \\
\hline \multicolumn{3}{|c|}{ Geographic Area (district) } & 0.304 \\
\hline Tribal & $45(29.8)$ & $36(18.0)$ & \\
\hline Charsadda & $15(9.9)$ & $40(20.0)$ & \\
\hline Bannu DI Khan & $13(8.6)$ & $26(13.0)$ & \\
\hline Nowshera & $11(7.3)$ & $14(7.0)$ & \\
\hline Peshawar & $19(12.6)$ & $24(12.0)$ & \\
\hline Swabi & $9(6.0)$ & $24(12.0)$ & \\
\hline Malakand & $10(6.6)$ & $14(7.0)$ & \\
\hline Mardan & $15(9.9)$ & $10(5.0)$ & \\
\hline Kohat & $1(0.7)$ & $12(6.0)$ & \\
\hline Dir Chitral etc. & $13(8.6)$ & - & \\
\hline \multicolumn{3}{|l|}{ Age (yrs) } & 0.931 \\
\hline $20-40$ & $24(15.9)$ & $14(7.0)$ & \\
\hline $41-50$ & $42(27.8)$ & $68(34.0)$ & \\
\hline $51-60$ & $41(27.2)$ & $68(34.0)$ & \\
\hline $60+$ & $44(29.1)$ & $50(25.0)$ & \\
\hline \multicolumn{3}{|l|}{ Occupation } & 0.786 \\
\hline Driver & $9(6.0)$ & $14(7.0)$ & \\
\hline Farmer & $45(29.8)$ & $77(38.5)$ & \\
\hline Labour & $39(25.8)$ & $34(17.0)$ & \\
\hline Odd jobs & $44(29.1)$ & $37(18.5)$ & \\
\hline Farmer/labour & $14(9.3)$ & $38(19.0)$ & \\
\hline \multicolumn{3}{|l|}{ Tobacco type used } & 0.853 \\
\hline Naswar & $142(94.0)$ & $200(100.0)$ & \\
\hline Cigarettes & $55(36.4)$ & $61(30.5)$ & \\
\hline Other types & $46(30.5)$ & $40(20.0)$ & \\
\hline \multicolumn{3}{|c|}{ Age at 1 st exposure (yrs) } & 0.45 \\
\hline$\leq 15$ & $66(43.7)$ & $74(37.0)$ & \\
\hline $16-20$ & $57(37.7)$ & $114(57.0)$ & \\
\hline $21-25$ & $11(7.3)$ & - & \\
\hline $25+$ & $17(11.3)$ & $12(6.0)$ & \\
\hline \multicolumn{3}{|l|}{ Daily use } & 0.931 \\
\hline Mild & $54(35.8)$ & $142(71.0)$ & \\
\hline Moderate & $62(41.1)$ & $33(16.5)$ & \\
\hline Heavy & $9(6.0)$ & $13(6.5)$ & \\
\hline
\end{tabular}

Thirty four percent $(34 \%)$ of patients were in the age range of 41-50 years; same percentage (34\%) was in the age range of 51-60 years, while $25 \%$ of the patients were in the range of $60+$ years of age. Highest incidence (20\%) of oral cancer was observed in district Charsadda, followed by Tribal areas (18\%), Southern districts (Bannu and DI Khan) (13\%), Swabi and Peshawar (12\% each). To estimate the socioeconomic status and occupational exposure profession of the subjects was noted. Almost all the patients were having hard jobs like driving, farming and other laborious jobs. Highest incidence $(57.5 \%)$ was observed in farmers of which $19 \%$ were those involved in tobacco farming or working labor in local tobacco industry. Several aspects of tobacco use habit were noted including type of tobacco product used, age at 1st exposure and amount of tobacco used per day. Cases and control were having similar tobacco habits ( $\mathrm{t}$ test $\mathrm{p}$ values $=0.853$, 0.45 and 0.931 for types of tobacco used (naswar, both cigarrete along with naswar, and other types), age at first exposure, and amount of tobacco used respectively. All the patients were naswar addicts, while $30.5 \%$ were using cigarretes along with naswar. Twenty percent of the patients were using other tobacco products such as chillum (huqqa) and charas/cannabis filled cigarettes. $37 \%$ patients started tobacco at the age of 10-15 years, while $57 \%$ started at the age of between 16-20 years, with mean age of 17 years. Subjects were divided into three categories on the basis of amount of tobacco used per day. Mild users were those taking less than 0.5 packs to 1.5 packs of either naswar or cigarettes alone or in combination. Moderate users were those taking more than 1.5 packs to 3 packs of either naswar or cigarettes alone or in combination. Heavy users were those using more than 4 packs of either naswar or cigarettes alone or in combination. Majority (71\%) of the patients were mild users followed by moderate users $(16.5 \%)$. Only about $7 \%$ were heavy users.

\section{Association with susceptibility to esophageal cancer}

The allele frequencies and genotypes of GSTs and CYP1A1 rs4646903 polymorphism of both control and oral cancer cases are given in Table 2. The distribution of GSTM1 and GSTT1 genotypes were significantly different between the cases and controls groups (Pearson chi Square $\chi^{2} 0.05,2=0.000, p>0.05$ ), while it was not significant in case of CYP1A1 rs4646903 ( $\mathrm{p}=0.762$ ). When analyzed for individual genes the prevalence of null genotypes of GSTM1 and GSTT1 was more in cases $(79.5 \%$ and $47.5 \%$ respectively) when compared to controls (57\% and $23.2 \%$ respectively). Null genotypes of both GST genes were having almost 3 -fold increased risk of oral cancer compared with wild type, which slightly increased when OR were adjusted for confounding factors such as tobacco use habits, age and area of residence etc. The prevalence of CYP1A1 rs4646903 gene was more in cases $(\mathrm{N}=76)$ as compared to control $(\mathrm{N}=55)$. However the association was weak and non-significant $(\mathrm{OR}=1.07$, p-value 0.762 ), with little effect of confounding factors when adjusted for them (Table 2). Similarly when analyzed for two GST gene combinations the association further increased to $(3.422(1.890-6.194)$, p-value $=0.000)$ and (8.986 (4.424-18.253), p-value 0.000) for GSTM/GSTT

1148 Asian Pacific Journal of Cancer Prevention, Vol 16, 2015 
GSTM1, GSTT1 and CYP1A1 Gene Variants and Oral Cancer Risk in Pashtun Population of Pakistan. Table 2. Crude and Adjusted Odds Ratios (OR) of GSTs and CYP1A1 and Oral Cancer

\begin{tabular}{|c|c|c|c|c|c|c|}
\hline $\begin{array}{l}\text { Genotype/allele } \\
\text { Genetic polymorphism }\end{array}$ & $\begin{array}{c}\text { Cases N } \\
(\%)\end{array}$ & $\begin{array}{c}\text { Control N } \\
(\%)\end{array}$ & $\begin{array}{l}\text { Crude OR } \\
(95 \% \mathrm{CI})\end{array}$ & p-value & $\begin{array}{l}\text { Adjusted OR } \\
\quad(95 \% \mathrm{CI})\end{array}$ & p-value \\
\hline \multicolumn{7}{|l|}{ GSTM1 } \\
\hline Wild type & $41(20.5)$ & $65(43.0)$ & Ref. & & & \\
\hline Null & $159(79.5)$ & $86(57.0)$ & $2.931(1.831-4.693)$ & 0 & $3.019(1.861-4.898)$ & 0 \\
\hline \multicolumn{7}{|l|}{ GSTT1 } \\
\hline Wild type & $105(52.5)$ & $116(76.8)$ & Ref. & & & \\
\hline Null & $95(47.5)$ & $35(23.2)$ & $2.999(1.876-4.793)$ & 0 & $3.011(1.865-4.862)$ & 0 \\
\hline \multicolumn{7}{|l|}{ CYP1A1 } \\
\hline Wild type & $124(62.0)$ & $96(63.6)$ & Ref. & & & \\
\hline Polymorphism & $76(38.0)$ & $55(36.4)$ & $1.070(0.691-1.657)$ & 0.762 & $1.121(0.717-1.752)$ & 0.617 \\
\hline \multicolumn{7}{|l|}{ Combinations 2 genes } \\
\hline GSTM/GSTT both wild type & $20(10.0)$ & $51(33.8)$ & Ref. & & & \\
\hline GSTM/GSTT either 1 expressed & $124(62.0)$ & $79(52.3)$ & $3.422(1.890-6.194$ & 0 & $3.627(1.981-6.642)$ & 0 \\
\hline GSTM/GSTT both null & $76(38.0)$ & $21(13.9)$ & $8.986(4.424-18.253)$ & 0 & $9.261(4.495-19.079)$ & 0 \\
\hline \multicolumn{7}{|l|}{ Combination 3 genes } \\
\hline GTSM/GSTT/ CYP1A1 wild type & $9(4.5)$ & $27(17.9)$ & Ref. & & & \\
\hline GSTM/GSTT null and CYP1A1 wild type & $69(34.5)$ & $53(35.09)$ & $4.145(1.871-9.183)$ & 0 & $4.576(2.038-10.273)$ & 0 \\
\hline GSTM/GSTT either null and CYP1A1 & $103(51.5)$ & $64(42.4)$ & $5.182(2.382-11.273)$ & 0 & $5.593(2.530-12.362)$ & 0 \\
\hline All 3 gene polymorphisms & $19(9.5)$ & $7(4.6)$ & $8.143(2.647-25.054)$ & 0 & $16.10(3.854-67.260)$ & 0 \\
\hline
\end{tabular}

either one expressed or GSTM/GSTT both null genotypes, respectively. This association further strengthened when adjusted for confounding factors; with 2-fold increase for GSTM/GSTT both null genotype. When all three genes were analyzed in combination the association further strengthened, with individuals possessing all three gene variant alleles showing a 16-fold increased risk of oral cancer as compared to control, in the presence of other confounding risk factors.

\section{Discussion}

It is well recognized fact that some individuals are more susceptible to certain types of cancers within similar environmental conditions. Different factors are involved in the initiation of carcinogenesis. These include but not limited to polymorphisms in genes responsible for the expression of carcinogen metabolizing enzymes, environmental exposure (such as tobacco use and alcohol consumption) and dietary and life style habits of the individuals. GSTs and CYP1A1 are among the most important enzymes involved in the processing of tobacco related carcinogens. However, polymorphisms in GSTM1, GSTT1 and CYP1A1 genes and their association with oral cancer have shown varying results (Nosheen et al., 2014). Association has been reported in Asians but not in Caucasian population in several meta-analysis studies. These observations have shown the importance of ethnic differences among the study population (Hirschhorn, 2002, Gupta and Johnson, 2014). Our study has thrown light on the involvement of genetic, ethnic and demographic factor differences in the incidence of oral cancer. Present data shows that genetic polymorphisms in GSTM1, GSTT1 and CYP1A1 genes have important contribution towards the occurrence of oral cancer in Pashtun population. GSTM1 and GSTT1 have shown a 3-fold independent association, while CYP1A1 is weakly involved (see table 1). Combined effects of both GSTs alone, and in combination with CYP1A1, further increase the association. The risk is 8-fold high in those patients that have variant alleles of all three genes $(\mathrm{OR}=8.143$ (2.647-25.054)), showing the importance of CYP1A1 gene. Similarly when adjusted for age, gender, place of residence, occupation, tobacco type used, amount of tobacco used per day and age at first exposure the risk further increased showing the importance of these environmental and demographic factors. The risk of oral cancer doubled $(\mathrm{OR}=16.10$ (3.854-67.260)), when these factors were adjusted in individuals that have variant alleles of all three genes. The occurrence of oral cancer increases with age, with incidence rates peaking at 70 years. In this study almost $70 \%$ of the patients were in the age range of 40-60 years. Regarding tobacco habits it was observed that hundred percent were exposed to naswar. About $87 \%$ were mild to moderate users, while mean age at first exposure was 17 years. This shows that majority of the patients were exposed for more than 30 years to tobacco carcinogens. Area of residence showed that Tribal belt, Charsadda, Peshawar and Swabi districts were having more cases of oral cancer as compared to other districts. This observation is consistent with increased exposure to tobacco in these districts due to tobacco farming (especially in Charsadda and Swabi) and naswar consumption. Similarly, undernutrition associated with low socioeconomic status has been an established risk factor for various types of cancers including that of oral cavity, and our data showed that almost $100 \%$ were having laborious low paid jobs. All these findings are consistent with previous studies that have shown association of GSTM1, GSTT1 and CYP1A1 genes, tobacco consumption (like naswar and cigarettes) and other risk factors with oral cancer. In conclusion, our study shows that the GSTM1, GSTT1 and CYP1A1 genes may be associated with the risk of oral cancer, especially in the presence of tobacco (naswar) use.

In conclusion, based on above mentioned findings, reducing consumption of tobacco (especially naswar in Pashtun population) and elevating the socioeconomic status must be regarded as the primary preventive strategies 
for the control of oral cancer in Khyber Pakhtunkhwa province. Similarly, projects should be designed by governmental agencies to screen for genetically susceptible individuals and awareness campaigns regarding genetic susceptibility and environmental risk factors be initiated in general public.

\section{Acknowledgements}

We acknowledge Institute of Radiotherapy and Nuclear Medicine (IRNUM), Peshawar for supply of blood samples. We also wish to thank Mr. Zahid Ali, Mr. Zahir Shah and Mr. Waheed-ur-Rahman, who facilitated the collection of control blood samples from different districts of Khyber Pakhtunkhwa. We also acknowledge Department of Zoology, University of Peshawar for provision of some of the laboratory facilities available at their end.

\section{References}

Abbas M, Srivastava K, Imran M, Banerjee M (2014). Association of CYP1A1 gene variants rs4646903 (T>C) and rs $1048943(\mathrm{~A}>\mathrm{G})$ with cervical cancer in a North Indian population. Eur J Obstet Gynecol Reprod Biol, 176, 68-74.

Amtha R, Ching CS, Zain R, et al (2009). GSTM1, GSTT1 and CYP1A1 polymorphisms and risk of oral cancer: a casecontrol study in Jakarta, Indonesia. Asian Pacific J Cancer Prev, 10, 21-26.

Ariyawardana A, Johnson NW (2013). Trends of lip, oral cavity and oropharyngeal cancers in Australia 1982-2008: overall good news but with rising rates in the oropharynx. $B M C$ Cancer, 13, 333 .

Balaram P, Sridhar H, Rajkumar T et al (2002). Oral cancer in southern India: the influence of smoking, drinking, paanchewing and oral hygiene. Int J Cancer, 98, 440-5.

Bhurgri Y, Bhurgri A, Nishter S, et al (2006). Pakistan - country profile of cancer and cancer control 1995-2004. J Pak Med Assoc, 56, 124-30.

Bile KM, Shaikh JA, Afridi HU, Khan Y (2010). Smokeless tobacco use in Pakistan and its association with oropharyngeal cancer. East Mediterr Health J, 16, 24-30.

Cha In-Ho, Park JY, Chung WY, et al (2007). Polymorphisms of CYP1A1 and GSTM1 genes and susceptibility to oral cancer. Yonsei Med J, 48, 233-9.

D'Errico A, Taioli E, Xhen X, et al (1996). Genetic metabolic polymorphisms and the risk of cancer: a review of the literature. Biomark, 1, 149-73.

Dikshit RP, Kanhere S (2000). Tobacco habits and risk of lung, oropharyngeal and oral cavity cancer: a population- based case-control study in Bhopal, India. Int J Epidemiol, 29, 609-14.

Gupta B, Johnson NW (2014). Emerging and established global life-style risk factors for cancer of the upper aero-digestive tract. Asian Pac J Cancer Prev, 15, 5983-91.

Hirschhorn JN, Lohmueller K, Byrne E, (2002). A comprehensive review of genetic association studies. Genet Med, 4, 45-61.

Masood N, Yasmin A, Kayani MA, (2013). Genetic deletions of GSTM1 and GSTT1 in head and neck cancer: review of the literature from 2000 to 2012. Asian Pac J Cancer Prev, 14, 3535-9.

Merchant A, Husain SS, Hosain M et al (2000). Paan without tobacco: an independent risk factor for oral cancer. Int $J$ Cancer, 86, 128-31.

Moore SR, Johnson NW, Pierce AM, Wilson DF (2000). The epidemiology of mouth cancer: a review of global incidence. Oral Dis, 6, 65-74.

Nair UJ, Nair J, Mathew B, Bartsch M (1999). Glutathione S-transferase M1 and T1 null genotypes as risk factors for oral leukoplakia in ethnic Indian betel quid/tobacco chewers. Carcinogenesis, 20, 743-48.

Nandakumar A, Thimmasetty KT, Sreeramareddy NM et al (1990). A population-based case-control investigation on cancers of the oral cavity in Bangalore, India. Br J Cancer, 62, 847-51.

Olshan AF, Weissler MC, Bell DA (2000). GSTM1, GSTT1, GSTP1, CYP1A1, and NAT1 polymorphisms, tobacco use, and the risk of head and neck cancer. Cancer Epidemiol Biomark Prev, 9, 185-91.

Park JY, Muscat JE, Kaur T, et al (2000). Comparison of GSTM polymorphisms and risk of oral cancer between AfricanAmerican and Caucasians. Pharmacogenetics, 10, 123-31.

Prokopczyk B, Cox JE, Hoffmann D, et al (1997). Identification of tobacco specific carcinogen in the cervical mucus of smokers and non-smokers. J Natl Cancer Inst, 89, 868-73.

Rao DN, Desai PB (1998). Risk assessment of tobacco, alcohol and diet in cancers of base tongue and oral tongue-a case control study. Indian J Cancer, 35, 65-72.

Rickert WS, Joza PJ, Trivedi AH et al (2009). Chemical and toxicological characterization of commercial smokeless tobacco products available on the canadian market. Regul Toxicol Pharmaco, 53, 121-33.

Sabitha K, Reddy MV, Jamil K (2010). Smoking related risk involved in individuals carrying genetic variants of CYP1A1 gene in head and neck cancer. Cancer Epidemiol, 34, 587-92.

Sharma A, Mishra A, Das BC, Sardana S, Sharma JK (2006). Genetic polymorphism at GSTM1 and GSTT1 gene loci and susceptibility to oral cancer. Neoplasma, 53, 309-15.

Sreelekha TT, Ramadas K, Pandey M, et al (2001). Genetic polymorphism of CYP1A1, GSTM1 and GSTT1 genes in Indian oral cancer. Oral Oncol, 37, 593-8.

Tanimoto K, Hayashi S, Yoshiga K, Ichikawa T (1999). Polymorphisms of the CYP 1A1 and GSTM1 gene involved in oral squamous cell carcinoma in association with a cigarette dose. Oral Oncol, 35, 191-6.

Velema JP, Ferrera A, Figueroa M, et al (2002). Burning wood in the kitchen increases the risk of cervical neoplasia in HPV-infected women in Honduras. Int J Cancer, 97, 536-41.

Warnakulasuriya S, Sutherland G, Scully C (2005). Tobacco, oral cancer, and treatment of dependence. Oral Oncol, 41, 244-60.

Wogan GN, Hecht SS, Felton JS, Conney AH, Loeb LA (2004). Environmental and chemical carcinogenesis. Semin Cancer Biol, 14, 473-86.

Xia L, Gao J, Liu Y, et al (2013). Significant association between CYP1A1 T3801C polymorphism and cervical neoplasia risk: a systematic review and meta-analysis. Tumor Biol, 34, 223-30.

Znaor A, Brennan P, Gajalakshmi V et al (2003). Independent and combined effects of tobacco smoking, chewing and alcohol drinking on the risk of oral, pharyngeal and esophageal cancers in Indian men. Int J Cancer, 105, 681-6.

Zakiullah, Saeed M, Ali S et al (2014). Genetic susceptibility to esophageal cancer due to CYP1A1 gene variant rs4646903 in tobacco addicted patients of Pashtun ethnicity: a case control study in Khyber Pakhtunkhwa province of Pakistan. Asian Pac J Cancer Prev, 15, 6715-20. 